\title{
Morphology and Distribution of Spinothalamic Lamina I Neurons in the Monkey
}

\author{
En-Tan Zhang and A. D. Craig \\ Division of Neurobiology, Barrow Neurological Institute, Phoenix, Arizona 85013
}

\begin{abstract}
Lamina I spinothalamic tract (STT) neurons were identified by retrograde labeling with cholera toxin subunit b (CTb) in monkeys. On the basis of the criteria of somatal shape and dendritic orientation in horizontal sections used in prior work in the cat, three distinct morphological types were recognized: fusiform $(F)$ cells with spindle-shaped somata and two main longitudinal dendritic arbors; pyramidal $(P)$ cells with triangular somata and three main dendrites oriented primarily longitudinally; and multipolar (M) cells with polygonal somata and four or more dendrites directed longitudinally and mediolaterally. Some cells had transitional shapes, but cells with indeterminate shapes and a few with small round, unipolar, or eccentric somata were grouped as unclassified $(U)$. Greater variation appeared in the monkey than had been seen in the cat, and more subtypes
\end{abstract}

were noted. The overall proportions of these cell types were: $47 \% \mathrm{~F}, 27 \% \mathrm{P}, 22 \% \mathrm{M}$, and 5\% U. Differential longitudinal distributions were found over the length of the spinal cord (from the second cervical through the first coccygeal segments). Pyramidal and multipolar cells together predominated in the enlargements, whereas fusiform cells predominated in thoracic segments. We conclude that three distinct morphological types of lamina I STT cells are present in the monkey as in the cat. Considered with other recent findings, the present results support the possibility that these three cell types may correspond to distinct physiological classes of nociceptive and thermoreceptive lamina I STT cells.

Key words: dorsal horn; spinothalamic; sensory neurons; nociception; thermoreception; functional specialization
Lamina I, the thin marginal layer overlying the substantia gelatinosa in the superficial spinal dorsal horn (Rexed, 1952), is an integral component of the central representation of pain and temperature sensibilities (Perl, 1984; Willis, 1985; Craig, 1996). It contains a unique concentration of nociceptive and thermoreceptive neurons (Christenson and Perl, 1970), and it is the source of about one-half of the spinothalamic tract (STT; Carstens and Trevino, 1978; Willis et al., 1979; Apkarian and Hodge, 1989; Craig et al., 1989). Lamina I STT axons ascend in the lateral STT, which is critical for pain and temperature sensation (Nathan and Smith, 1979; Norrsell, 1979; Craig, 1991; Ralston and Ralston, 1992). In primates, they terminate in a dedicated nociceptive and thermoreceptive relay nucleus in posterolateral thalamus (VMpo; Craig et al., 1994; Zhang and Craig, 1996) that projects to dorsal insular cortex and to area 3a (Craig et al., 1995), and they terminate also in a region of posteromedial thalamus that projects to anterior cingulate cortex (MDvc; Ganchrow, 1978; Craig and Zhang, 1996). These cortical areas are strongly activated in PET studies of pain and temperature sensation (Jones et al., 1991; Talbot et al., 1991; Casey et al., 1996; Craig et al., 1996).

The present anatomical study of the morphology of lamina I STT cells in the primate was motivated by two considerations. First, previous retrograde labeling studies in cat and rat have produced conflicting results. Even though Golgi studies in cat (Gobel, 1978) and rat (Lima and Coimbra, 1986) both described similar cell types in lamina I (fusiform, pyramidal, and multipo-

Received Sept. 27, 1996; revised Feb. 6, 1997; accepted Feb. 10, 1997.

This study was supported by National Institutes of Health Grant NS 25616 and by the Atkinson Pain Research Fund administered by the Barrow Neurological Foundation. We thank K. Krout and S. Jordan for technical assistance and Dr. M. Wikstrom for generously supplying monoclonal antibodies against CTb.

Correspondence should be addressed to Dr. A. D. Craig, Division of Neurobiology, BNI, 350 West Thomas Road, Phoenix, AZ 85013.

Copyright (C) 1997 Society for Neuroscience $0270-6474 / 97 / 173274-11 \$ 05.00 / 0$ lar), a retrograde labeling study of lamina I STT cells in the rat reported that they were mostly pyramidal cells (Lima and Coimbra, 1988), whereas a comparable study in the cat found fusiform, pyramidal, and multipolar lamina I STT cells (Zhang et al., 1996). Both studies utilized cholera toxin subunit b (CTb), which provides excellent retrograde morphological definition (Ericson and Blomqvist, 1988). Previous comparative data in the primate are limited and inconsistent. Similar cell types were not reported in lamina I by Golgi studies of monkey (Beal et al., 1981) or human (Schoenen, 1982; Bowsher and Abdel-Maguid, 1984) dorsal horn; however, in an early study using WGA*HRP "fusiform, pyriform or triangular" lamina I STT cells were noted, although detailed observations were not made (Willis et al., 1979).

Second, the morphological identification of distinct lamina I STT cell types in primates may be relevant to the functional characterization of this pathway. In other sensory systems, morphologically distinct cell types correspond to physiologically distinct classes (for example, see Tamamaki et al., 1995). Although earlier physiological studies of lamina I STT cells in the monkey described only nociceptive-specific (NS) or wide dynamic range (WDR, responsive to both noxious and innocuous stimuli) cell classes (Willis et al., 1974; Price et al., 1978; Ferrington et al., 1987), recent work has shown that primate lamina I STT cells that project to VMpo include NS cells, cooling-specific (COLD) cells, and polymodal nociceptive (HPC) neurons responsive to heat, pinch, and cold (Dostrovsky and Craig, 1996). These are the same physiological classes of lamina I STT cells found in the cat (Craig and Kniffki, 1985; Craig, 1996), which preliminary intracellular labeling observations suggest may correspond to fusiform, pyramidal, and multipolar cells, respectively (Han and Craig, 1994). Thus, the possibility that such a structural/functional correlation may be a general mammalian feature of lamina I provided additional reason to determine whether lamina I STT cells in the 
primate can be classified morphologically into the same categories found in the cat. Accordingly, using the same methods as in our prior work (Zhang et al., 1996), we have examined the morphology and distribution of retrogradely CTb-labeled lamina I STT cells in the monkey.

A preliminary report of this work has been made (Zhang and Craig, 1995).

\section{MATERIALS AND METHODS}

Experiments were performed in five adult Old World cynomolgus monkeys (Macaca fascicularis). In addition, similar spinal material from one New World owl monkey (Aotus trivirgatus) was available from a parallel study, in which the primary purpose was retrograde labeling of trigeminothalamic neurons (Blomqvist et al., 1995). The animals were anesthetized with sodium pentobarbital $(40 \mathrm{mg} / \mathrm{kg}$ i.p., with i.v. supplements) and placed in a stereotaxic apparatus. Body temperature was maintained at $36^{\circ} \mathrm{C}$ with a heating pad and an infrared lamp. Under aseptic conditions, a window in the skull was made to provide access to the right or left thalamus. The stereotaxic coordinates of the boundaries of the somatosensory thalamus were identified electrophysiologically by recording during several penetrations with a tungsten-in-glass microelectrode. Injection sites were chosen by extrapolation from this map to include nearly all of the dorsal thalamus, but particularly the major lamina I STT termination sites identified by prior anterograde tracing studies: the posterior part of the ventral medial $n$. (VMpo), the ventral posterior inferior $n$. (VPI), and the ventral caudal part of the medial dorsal n. (MDvc; Craig et al., 1994). Two to eight injections of an aqueous solution of 0.4 to $1 \%$ cholera toxin subunit b (CTb; Sigma) were made with a Hamilton syringe for a total of 2-10 $\mu \mathrm{l}$. The needle was left in place for 5-15 min after each injection. The monkeys were allowed to survive 7-28 d.

After survival, the monkeys were deeply anesthetized and perfused transcardially with 11 PBS $(0.1 \mathrm{M}$ phosphate buffer, $\mathrm{pH} 7.4$, with $0.9 \%$ saline) containing 15,000 IU heparin, followed by 11 of $4 \%$ paraformaldehyde and $0.2 \%$ picric acid in $\mathrm{PB}$ and then $214 \%$ paraformaldehyde and $0.05 \%$ glutaraldehyde with $10 \%$ sucrose in PB. The brain and spinal cord were removed and postfixed in the last solution for $4 \mathrm{hr}$ and then stored in $30 \%$ sucrose in $\mathrm{PB}$ for $1-3 \mathrm{~d}$ at $4^{\circ} \mathrm{C}$.

Serial $50 \mu \mathrm{m}$ frozen sections were cut in the transverse plane through the thalamus, and serial $50 \mu \mathrm{m}$ sections were cut in the horizontal plane from each spinal segment from $\mathrm{C} 2$ to the first coccygeal segment. A one-in-three series of thalamic sections was stained with thionin, and all other sections were processed immunohistochemically with the $\mathrm{ABC}$ technique for CTb labeling as in the prior study (Zhang et al., 1996). The sections were preincubated in a solution of $4 \%$ normal horse serum for 30 min and then placed in monoclonal mouse anti-CTb antiserum (1:1 mixture of CT2 and CT9 ascites, courtesy of Dr. Marianne Wikstrom) diluted 1:600 in horse serum for $2 \mathrm{~d}$ at $4^{\circ} \mathrm{C}$. Biotinylated horse anti-mouse $\mathrm{IgG}$ (Vector 1:400) was used as the second antibody for $60 \mathrm{~min}$. The sections were then incubated with ABC (Vector Elite kit, 1:100) for 2-4 $\mathrm{hr}$ and reacted in a solution of $0.025 \%$ diaminobenzidine and $0.003 \%$ $\mathrm{H}_{2} \mathrm{O}_{2}$ in PBS for 10-20 min. Finally the sections were washed and mounted, air-dried overnight, and coverslipped with DPX.

Drawings of labeled lamina I STT cells in three cynomolgus monkeys were made with a camera lucida at $400 \times$ using a $20 \times$ apochromatic objective. Digitized images were captured directly at high resolution $(3400 \times 2700)$ with a Leaf Microlumina scanner mounted on a Nikon Optiphot. The stored TIFF images were enhanced (in contrast and brightness), sharpened, and labeled using Adobe Photoshop. Corrections for double cell counts in the $50 \mu \mathrm{m}$ horizontal sections were not made because lamina I neurons are generally only $10-40 \mu \mathrm{m}$ in dorsoventral thickness, because they were classified and counted on the basis of somatal shape and primary dendritic origins rather than simply as labeled profiles, and because the relative proportions rather than the absolute numbers of the different cell types were of primary concern. Measurements of the number of primary dendrites and of the length and width of the somata along the primary axes were made from the camera lucida drawings of 50 neurons of each type that were chosen at random from the cervical and lumbar enlargements of three macaque cases and that were judged to be representative of the overall variety of shapes and orientations of labeled lamina I STT neurons across all the cases and segments observed. Statistical comparisons were made with a two-tailed $t$ test (Statsoft STATISTICA).

\begin{tabular}{|c|c|c|c|c|c|c|c|c|}
\hline \multirow[b]{2}{*}{ Case } & \multirow[b]{2}{*}{$\begin{array}{l}\text { Survival } \\
\text { (days) }\end{array}$} & \multicolumn{2}{|c|}{ Injections } & \multicolumn{5}{|c|}{ Labeled lamina I STT cells } \\
\hline & & No. & $\begin{array}{l}\text { Amount } \\
(\mu \mathrm{l})\end{array}$ & $\begin{array}{l}\mathrm{F} \\
(\%)\end{array}$ & $\begin{array}{l}\mathrm{P} \\
(\%)\end{array}$ & $\begin{array}{l}\mathrm{M} \\
(\%)\end{array}$ & $\begin{array}{l}\mathrm{U} \\
(\%)\end{array}$ & Total \\
\hline STM45 & 13 & 7 & 10 & 46 & 30 & 21 & 4 & 3404 \\
\hline STM46 & 7 & 2 & 2 & 47 & 28 & 23 & 2 & 1561 \\
\hline STM50 & 21 & 4 & 6 & 46 & 25 & 26 & 3 & 3569 \\
\hline STM52 & 21 & 5 & 8 & 40 & 28 & 28 & 4 & 2123 \\
\hline STM55 & 19 & 5 & 9 & 51 & 27 & 21 & 5 & 4479 \\
\hline STM57 & 22 & 8 & 14 & 49 & 27 & 18 & 6 & 4766 \\
\hline
\end{tabular}

\section{RESULTS}

In all six cases, cells in lamina I contralateral to the injection site were labeled with $\mathrm{CTb}$ over the entire length of the spinal cord (C2 through Co1). Intense retrograde CTb labeling was present in the cases in which more than $6 \mu$ l of tracer had been injected and with survival times around 3 weeks, even though the number of labeled cells varied somewhat between cases (Table 1). The locations of the dense cores of the injections are shown in Figure 1 at a single thalamic level for each case. The photomicrograph of this level in case STM55 shown in Figure 2 illustrates the broader spread of $\mathrm{CTb}$ from the dense injection cores. In an early case (STM46, owl monkey) in which a small injection was made and a short survival time was used, incomplete labeling was obtained that diminished in intensity at lower cord levels and that lacked the concentration in the lumbosacral enlargement characteristic of the other cases. The morphological observations in this New World monkey otherwise did not differ from the results in the Old World cynomolgus monkeys. The injections in four of the five other cases encompassed the targeted thalamic regions in both medial and lateral thalamus, but in the remaining case (STM52) the injection failed to include parts of the caudal aspect of VPL, VPI, and VMpo (for abbreviations, see Fig. 1 legend), and the number of labeled cells was reduced. The injection did not spread into contralateral thalamus or into the hypothalamus in any case. In three cases (STM45, STM50, and STM55) the injections spread into the dorsal aspect of the anterior pretectal area of the midbrain, but only very slightly (Figs. 1 and 2), and no obvious differences in the numbers or the proportions of labeled cells were attributable to such spread.

Over a dorsal to ventral sequence of serial horizontal sections through the superficial spinal dorsal horn, the CTb-labeled lamina I STT cells became numerous at the first sign of gray matter. A few labeled cells were present within the white matter overlying lamina I, near the entering dorsal root fibers. The majority of labeled lamina I cells were found in the region of the dorsal cap (Snyder, 1982), overlying the lateral third of the dorsal horn, where lamina I is $\sim 300 \mu \mathrm{m}$ thick and where lamina I STT cells are concentrated (Apkarian and Hodge, 1989; Craig et al., 1989). Labeled lamina I STT cells were present throughout the entire mediolateral extent of the superficial aspect of the dorsal horn, which particularly in the cervical and lumbosacral enlargements spanned only a few sections. In more ventral sections, labeled cells were limited to the most lateral and medial aspects of the substantia gelatinosa (lamina II), which was quite recognizable with brightfield or darkfield microscopy. Labeled cells in lamina II were very rare, consistent with prior studies (Carstens and Trevino, 1978; Willis et al., 1979; Craig et al., 1989). The portion of lamina I that extends ventrally along the extreme lateral aspect 


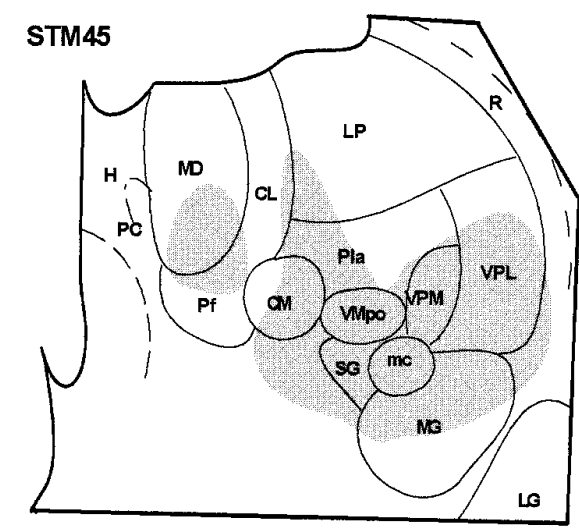

STM46

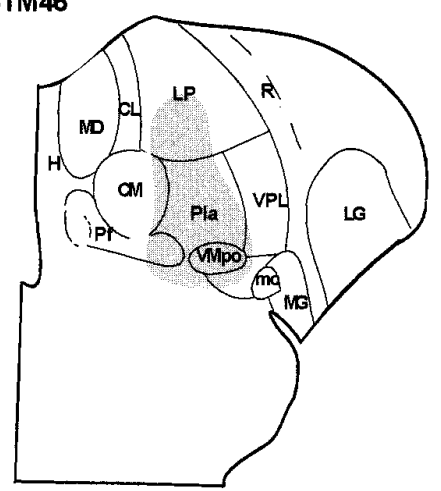

STM50

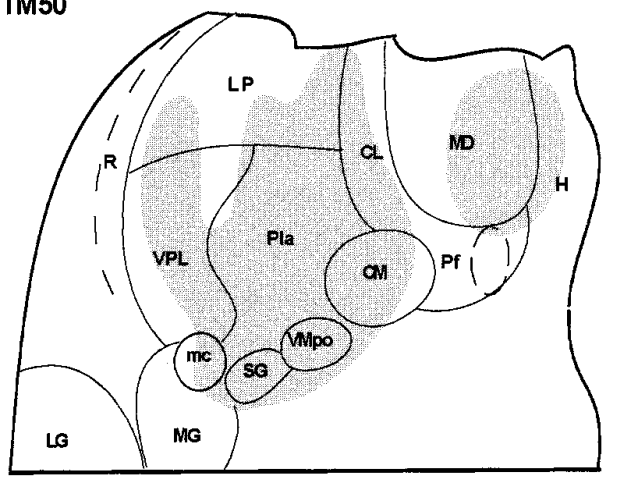

STM57

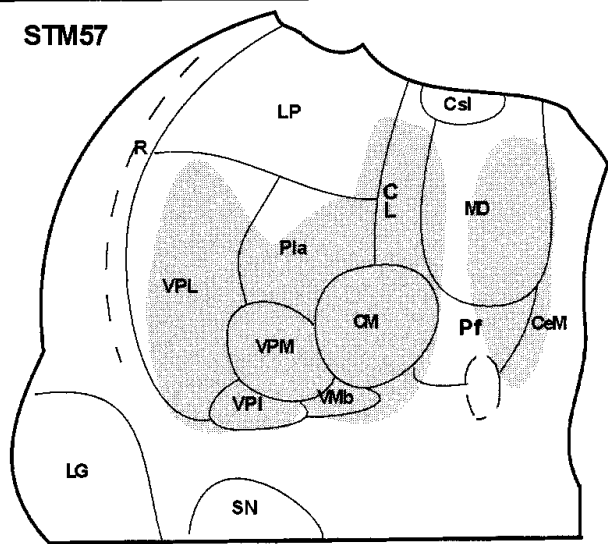

$5 \mathrm{~mm}$

Figure 1. Drawings depicting the dense portions of the CTb injections in each case. Except for case STM46 (owl monkey), injections were also made at more anterior levels, yet coverage of each of the main targets (VMpo, VPI, and MDvc) can be appreciated from the single frontal level shown. Abbreviations for Figures 1 and 2: $C e M$, central medial n.; $C s l$, central superior lateral n.; $C M$, center median; $H$, habenula; $L G$, lateral geniculate n.; $L P$, lateral posterior n.; $M D$, medial dorsal n.; $M G$, medial geniculate n.; $m c$, magnocellular part of the medial geniculate n.; $P C$, posterior commissure; $P f$, parafascicular n.; Pla, anterior pulvinar n.; $R$, reticular n.; $S G$, suprageniculate n.; $S N$ substantia nigra; $V P M$, ventral posterior medial n.; $V M b$, basal part of the ventral medial n.; VMpo, posterior part of the ventral medial n.; VPI, ventral posterior inferior n.; VPL, ventral posterior lateral n.

of the dorsal horn was not cut tangentially in horizontal sections, so that cell shape was more difficult to determine, but nearly all of the relatively few labeled cells in this portion were recognizable as bipolar fusiform cells.

The perikarya and primary dendrites of the CTb-labeled lamina I STT neurons were consistently well stained (Figs. 3, 4, and 6). The dendrites could be followed easily for up to $400 \mu \mathrm{m}$ or more. Consistent with previous observations in rat, cat, and monkey (Gobel, 1978; Price et al., 1978; Beal et al., 1981; Lima and Coimbra, 1986; Zhang et al., 1996), CTb-labeled lamina I STT cells in the monkey arborize in the horizontal plane. Most cells were oriented longitudinally, and their primary dendritic arbors were nearly always restricted to lamina I; few cells were observed with a dendrite extending into lamina II. In a small number of cells, one corner of the soma was angled slightly dorsally or ventrally, and the issuing dendrite continued in this direction. Nearly all labeled cells classified had complete perikarya with a clear nucleus and well labeled primary dendrites visible in one section, and it was seldom necessary to compare adjacent sections to determine cell shape.

\section{Morphological types of lamina I STT cells}

The cells were classified into three major classes (fusiform, pyramidal, and multipolar) based on the same criteria used in the prior

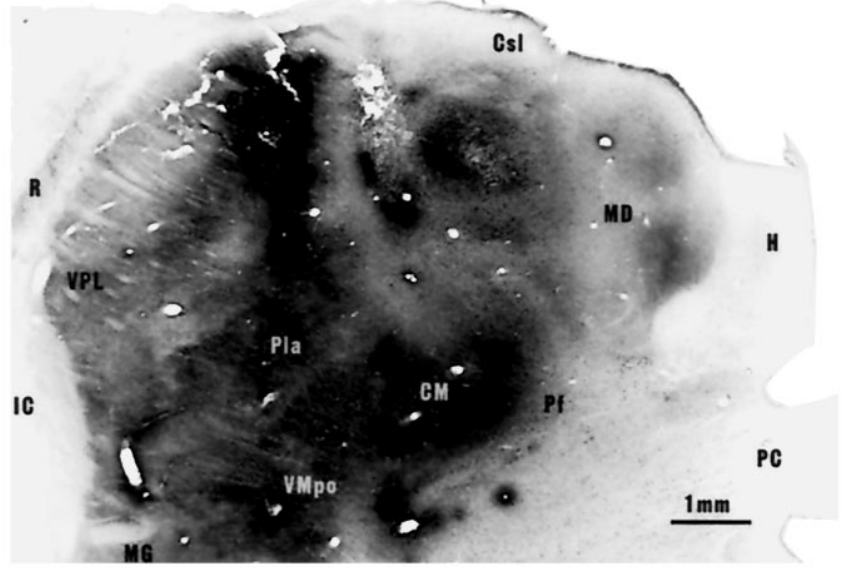

Figure 2. Photomicrograph illustrating $\mathrm{CTb}$ injections in the left thalamus of monkey STM55 in a frontal section processed for DAB. This is an adjacent section to that drawn in Figure 1. Three of the five injection tracks are visible. The injected $\mathrm{CTb}$ covered all of the medial and lateral thalamus with no spread to hypothalamus or the opposite side but with slight spread to the midbrain. 


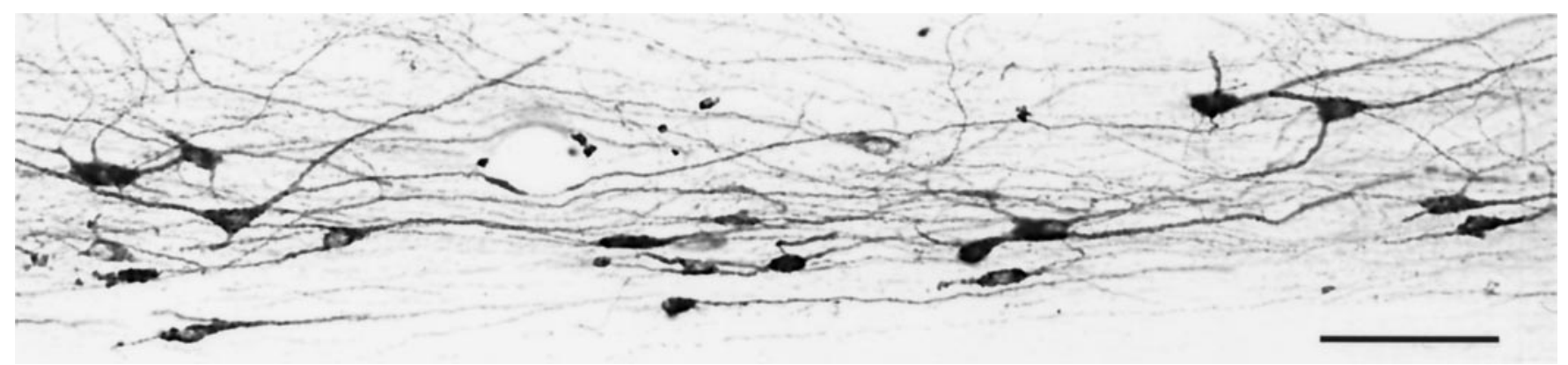

Figure 3. Photomicrograph of retrogradely CTb-labeled lamina I STT cells in the C8 segment in a horizontal section (medial up, caudal left). The perikarya and the proximal dendrites were well stained. Most cells had longitudinal perikarya and dendritic arbors oriented mainly rostrocaudally. Fusiform, pyramidal, and multipolar cells are visible. Scale bar, $100 \mu \mathrm{m}$.

Table 2. Lamina I STT cell measurements

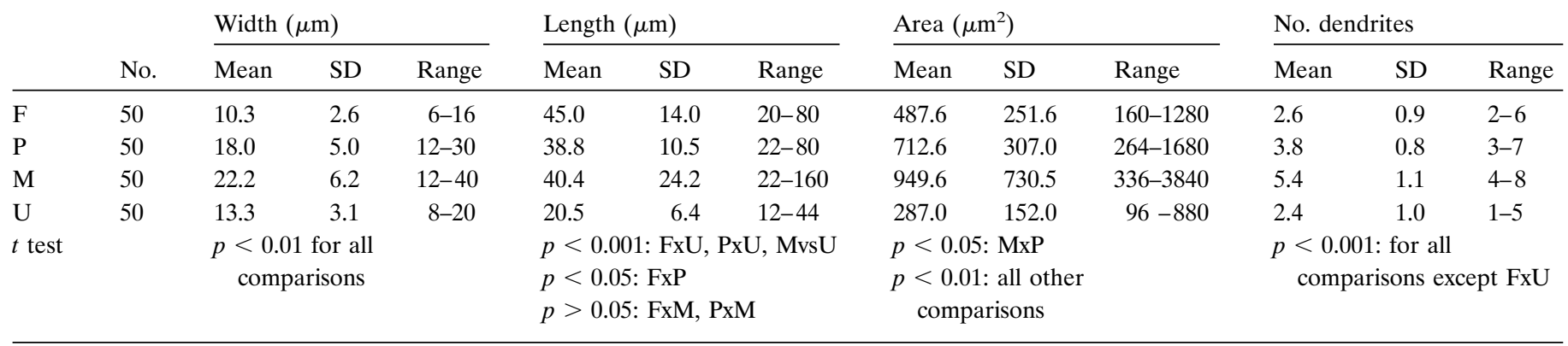

study in the cat, that is, on the basis of cell shape and primary dendritic orientation (Zhang et al., 1996). The appraised perikaryal shapes included poles determined by the origins of the major dendrites, defined as bases which tapered gradually into constant diameter, primary dendritic branches, but the branching patterns and orientations of the major dendrites were also noted, as well as any minor processes that emitted from the sides or poles of the somata. As described below, categorization was sometimes complicated by the variety of cell shapes observed and the occurrence of transitional shapes. A total of 19,709 contralateral retrogradely CTb-labeled lamina I STT cells was examined in 6 monkeys. On average, there were $47 \%$ fusiform, $27 \%$ pyramidal, and $22 \%$ multipolar cells (Tables 1 and 3 ). These classes were comprehensive; only about $5 \%$ of the labeled cells were placed in an "unclassified" set. The photomicrographs in Figures 4 and 6 and the drawings in Figure 5 are representative of the variety of the shapes, sizes, and orientations of the cells assigned to each type, as well as the subtypes noted. The dimensions of the somata and the numbers of dendrites of the three major morphological types also differed significantly, as shown in Table 2. There were no apparent differences between the Old World cynomolgus monkeys and the single New World owl monkey with respect to lamina I STT cell morphology.

\section{Fusiform cells}

These cells had spindle-shaped somata with elongated dendritic arbors extending from the two poles of the soma. They included the smallest lamina I STT cells observed. The great majority of fusiform cells were simple bipolar neurons with two major dendrites that extended in the longitudinal direction with little branching and little expansion in the mediolateral direction (Fig. 4, F1, F4; Fig. 5, F, a). Most fusiform cells had one primary dendrite arising from each pole of the soma, but some gave rise to two or more dendrites directly from one pole (Fig. 4, F3). Other fusiform cells were distinguished as a different subtype because they were more irregular and had perikarya or dendrites oriented at various angles between longitudinal and transverse (Fig. 5, $F$, $b$ ). Some of these had one longitudinal dendrite and another one directed mediolaterally, or one that reversed course and extended in the same longitudinal direction as the other dendrite. A few were observed that extended mediolaterally across the marginal zone. A small number of cells classed as fusiform had distinctly spindle-shaped somata and two longitudinal primary dendrites, but also issued another dendrite to the medial or lateral side that gave rise in a T-like fashion to two thin longitudinally extended dendrites (Fig. 4, F2).

\section{Pyramidal cells}

These cells had characteristically pyramidal or triangular somata with a primary dendrite issuing from each corner of the soma. The simplest had three dendrites (Fig. 4, P3, P4) and were oriented longitudinally, with the sharp apex pointing either rostrally or caudally; this subtype was the most common (Fig. 5, P,a). Occasionally, such cells were oriented at a slight angle between longitudinal and transverse. A second subtype had distinctly triangular somata but had dendrites that extended horizontally in all directions; these were often oriented transversely (Fig. 4, P1; Fig. 5, P, b). Most pyramidal cells gave rise to one dendrite from each corner, but occasionally two or three dendrites arose from the same origin at one corner (Fig. $4, P 1)$, and sometimes very fine dendrites emitted from the side of the cell body. A third, less common subtype consisted of cells with pyramidal somata that had an irregular protrusion from one corner directed medially or laterally, like a T- or L-shape (Fig. 4, P2; Fig. 5, P, c). 


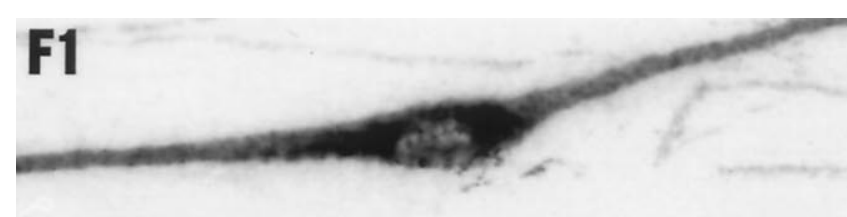

F3
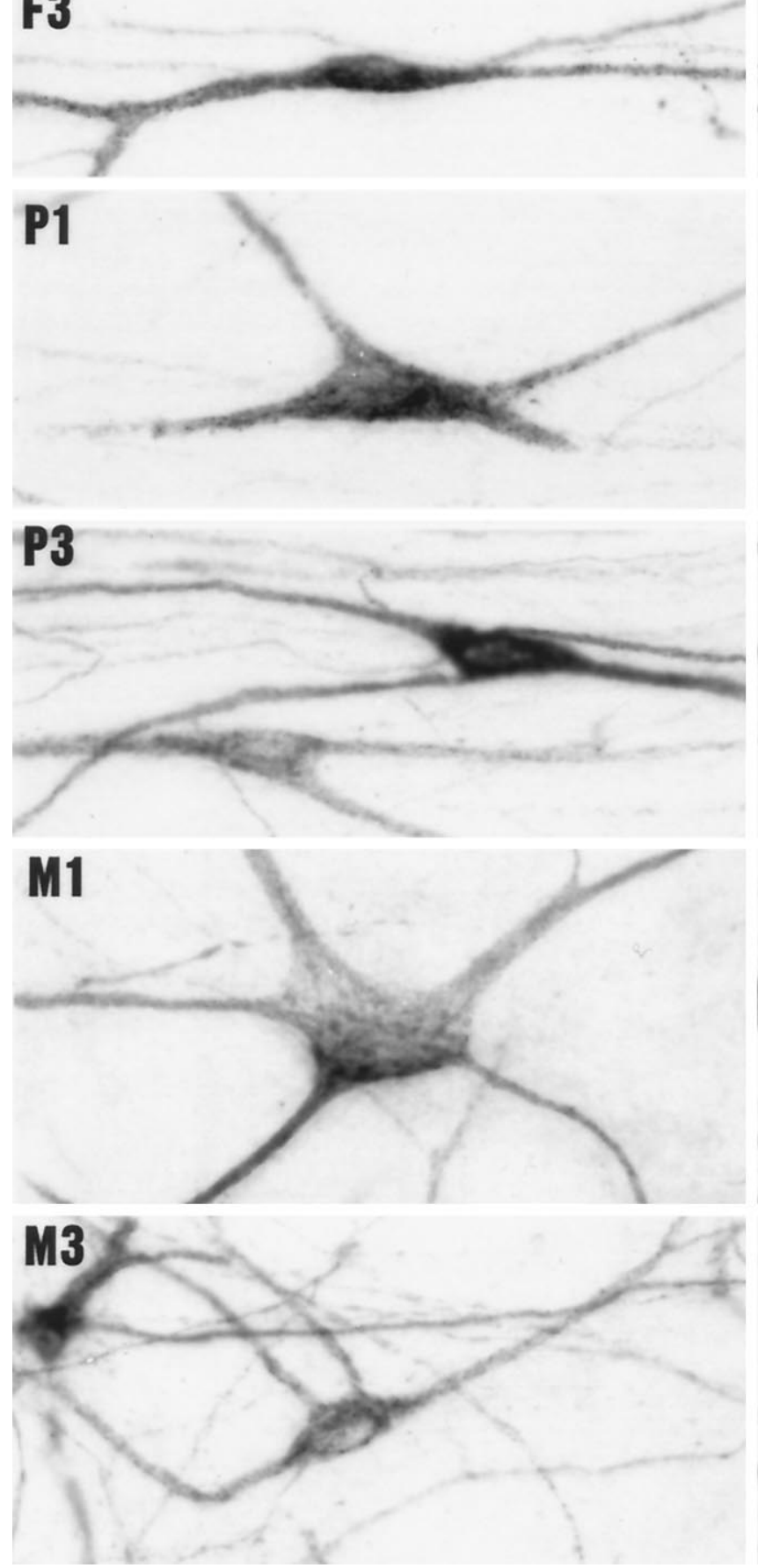

F2

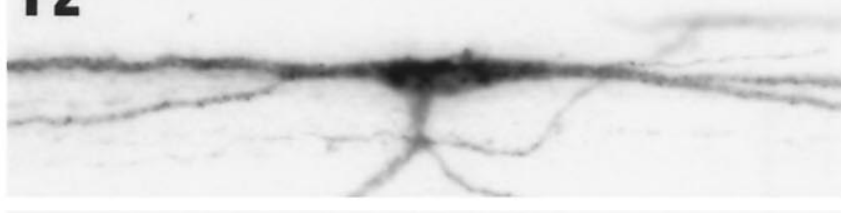

F4

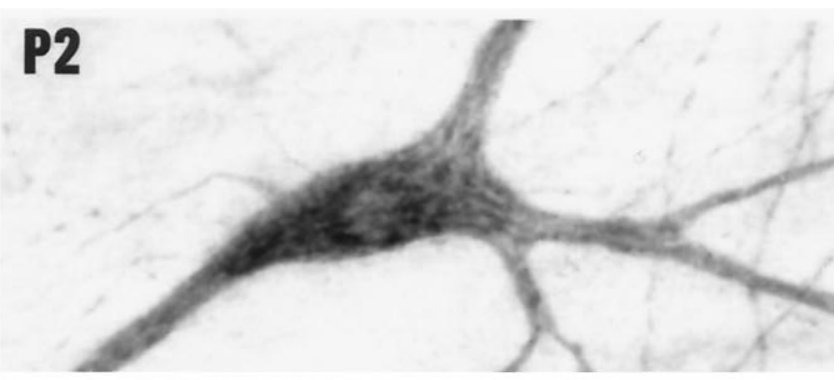

P4
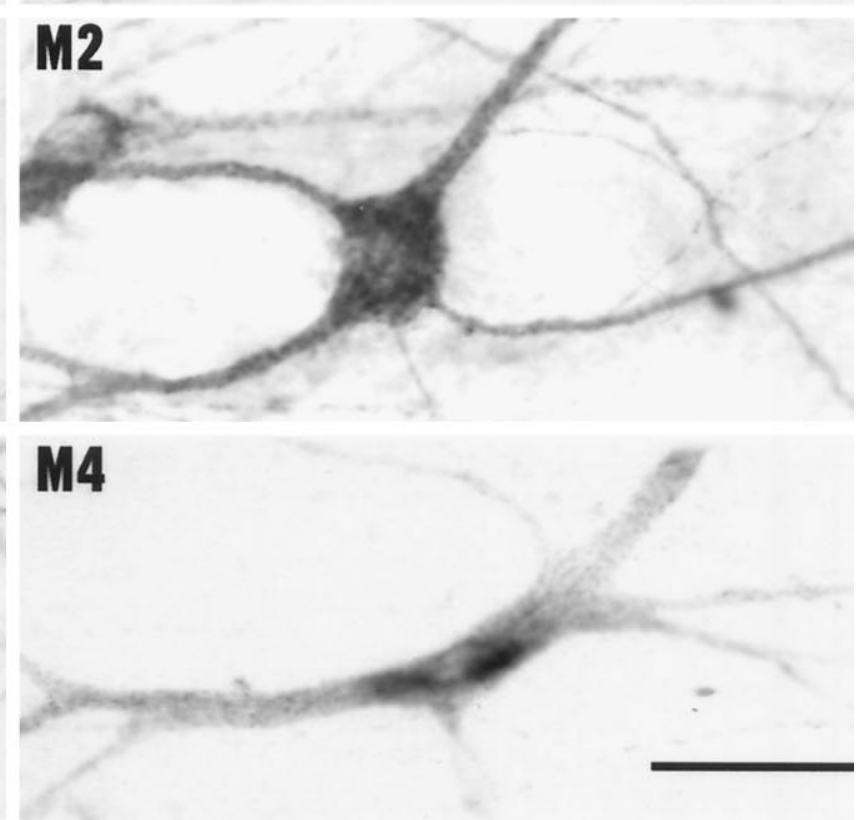

Figure 4. Photomicrographs showing varied examples of the three major types of labeled lamina I STT cells in $50 \mu \mathrm{m}$ horizontal sections (medial up, caudal left). $F$, Fusiform cells with spindle-shaped somata and two main dendrites; $P$, pyramidal cells with triangular somata and three main dendrites; $M$, multipolar cells with polygonal somata and several radiating dendrites. Scale bar, $50 \mu \mathrm{m}$. 
$\mathbf{F}$
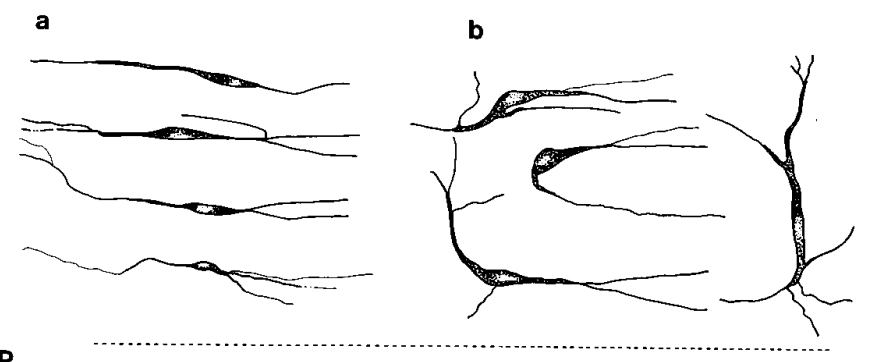

$\mathbf{P}$
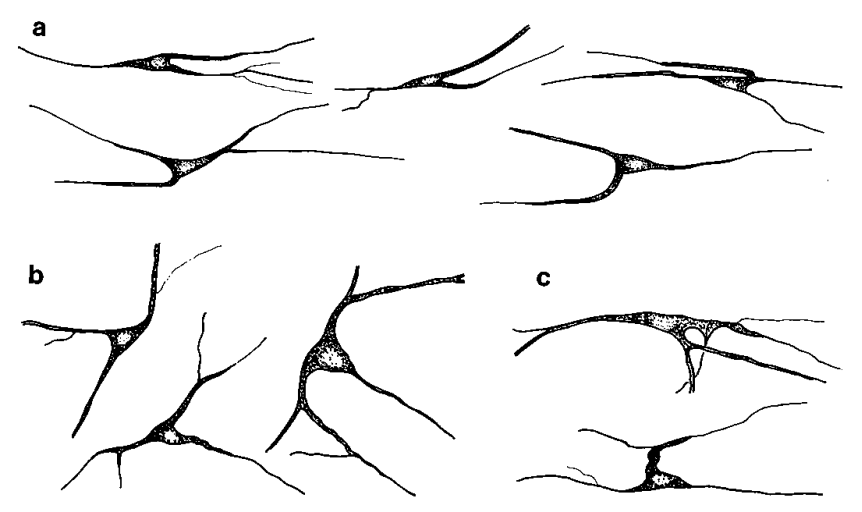

M
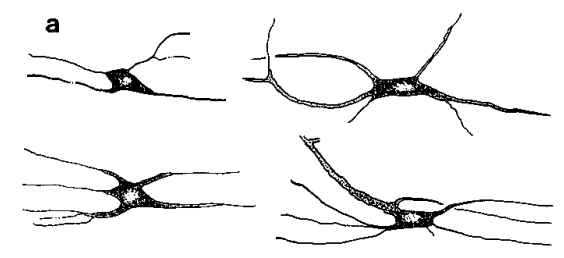

b
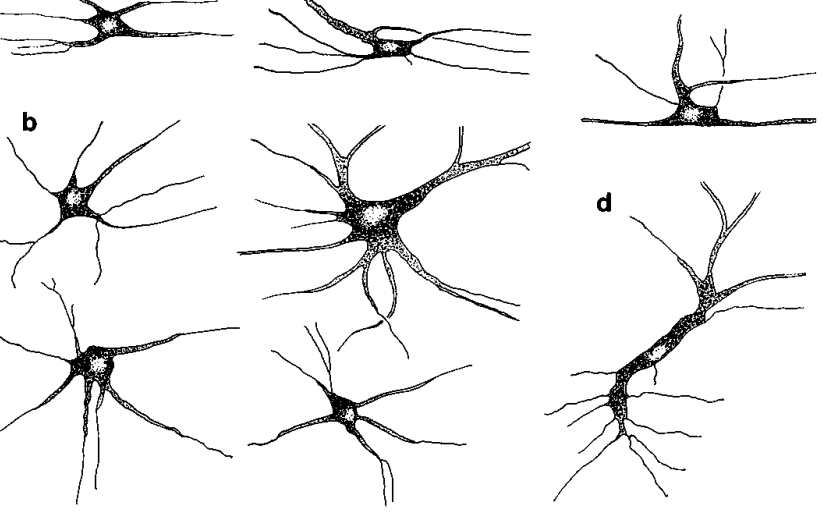

U
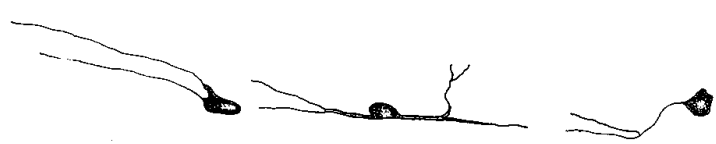

$100 \mu \mathrm{m}$

Figure 5. Camera lucida drawings of CTb-labeled lamina I STT cells in the horizontal plane (medial up and caudal left) representative of the variety of fusiform cells $(F)$ with their subtypes $[(a)$ regular and $(b)$ irregular], pyramidal $(P)$ cells with their subtypes $[(a)$ longitudinal pyramidal cells, $(b)$ triangular cells with radiating dendrites, and $(c)$ triangular cells with irregular protrusions], and multipolar $(M)$ cells with their subtypes [ $(a)$ quadrilateral cells, $(b)$ radiating cells, $(c) \pi$ - or T-like cells, and $(d)$ tubular cells], and unclassified cells $(U)$. Scale bar, $100 \mu \mathrm{m}$.

\section{Multipolar cells}

These cells had large, polygonal somata with several (at least four) dendrites that extended both mediolaterally and longitudinally. They were the largest of the three major types of lamina I STT cells. Four basic subtypes of multipolar cells were recognized. The most common were cells that had somata with a square, rectangular or quadrilateral shape and four dendrites that were oriented longitudinally (Fig. 4, M2; Fig. 5, M, a). The next most common subtype consisted of cells that had stellateshaped somata with five or more dendrites that radiated horizontally in all directions (Fig. 4, M1; Fig. 5, $M, b$ ). These included some of the largest cells observed. The third subtype of multipolar cells were $\pi$ - or T-shaped, having trapezoidal or polygonal somata and two longitudinal dendrites with two more dendrites that extended laterally or medially off to one side, one of which was sometimes of large diameter and oriented perpendicular to the otherwise longitudinal axis of the soma (Fig. 4, M3; Fig. 5, M, c). The least common subtype consisted of cells with tubular somata that had long cytoplasmic extensions (60 to well over $200 \mu \mathrm{m}$ ), and which had multiple dendrites that extended in any direction (Fig. 4, M4; Fig. 5, $M, d$ ).

\section{Unclassified cells}

A small number of cells in each case differed in morphology and could not be categorized into one of the above three types of neurons. Many of these cells were small and variously had round, oval, unipolar, or eccentric perikarya. The dendrites of these cells extended in any direction within lamina I. Cells that were incom- pletely stained or damaged (estimated at $<1 \%$ ) were also included in this category.

In addition, labeled cells were observed with shapes that were transitional between the major classes described above, i.e., they had somata characteristic of one form and dendritic arbors characteristic of another. About one-half of these were unclassifiable, whereas for others an assignment could be made based on the dominant character of the cell. For example, the cell in Figure $6 \mathrm{~A}$ had a nearly triangular shape, but the fourth, thinner dendrite had a distinct, albeit smaller, base (or pole) at its origin, and so this cell was categorized in accordance with its quadrilateral multipolar dendritic orientation. Similarly, the example in Figure $6 B$ also had a nearly triangular shape, but a radiating multipolar dendritic pattern and a multiangular soma. Last, the cell in Figure $6 C$ had a dendritic pattern resembling that of $\pi$-shaped multipolar cells, although the soma appeared fusiform and not multiangular. We estimate the overall number of such transitional cells as less than $5 \%$ of the total population.

\section{Distribution of the different types of lamina I STT cells}

The majority of lamina I STT cells were located in the dorsal cap. Labeled cells in the most lateral aspect of lamina I, which extends ventrally along the lateral aspect of the dorsal horn, were generally fusiform, although pyramidal cells were also observed there. All three types of cells were present in the middle portion. The largest cells were found in the medial portion of lamina I, and these were usually multipolar cells. The different types of lamina I STT cells appeared overall to be randomly intermixed; nonethe- 


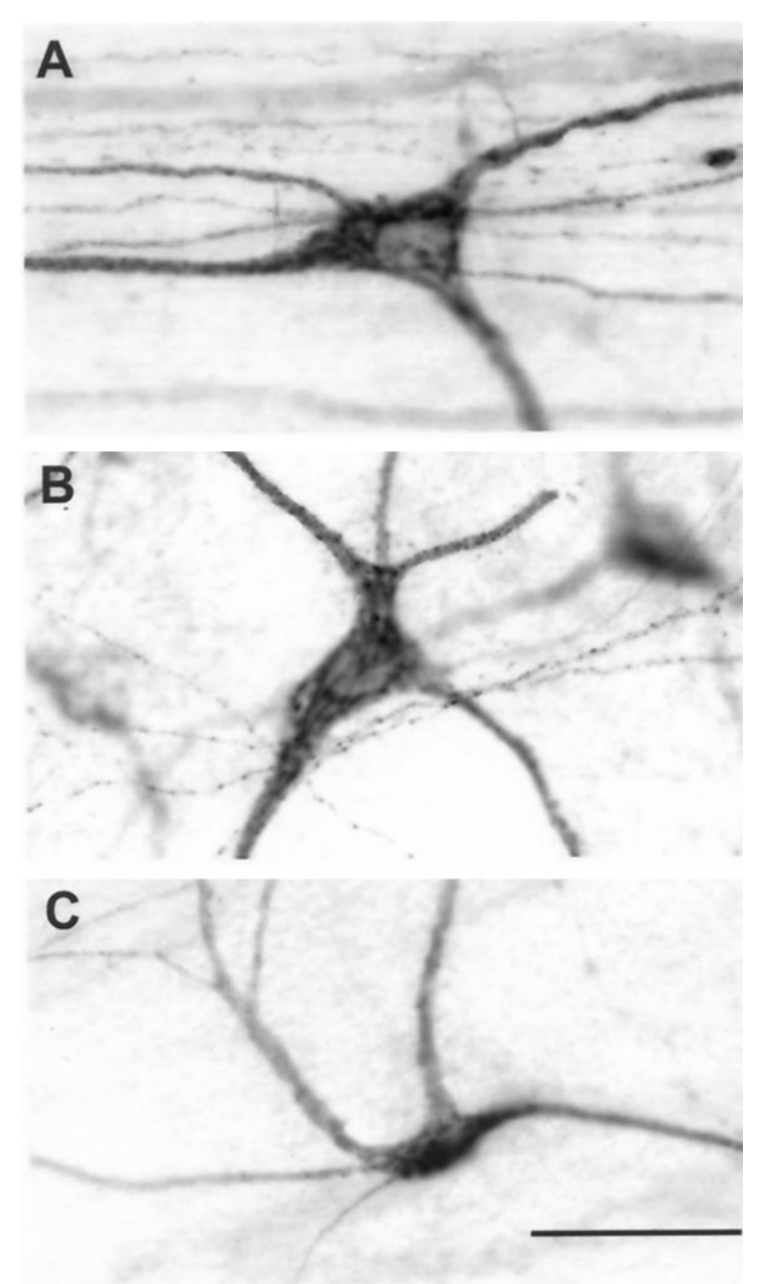

Figure 6. Photomicrographs showing examples of lamina I STT cells with transitional shapes (medial up, caudal left). A, A cell with a nearly triangular soma and with multipolar quadrilateral dendrites. $B$, A cell with a nearly triangular soma and with multipolar radiating dendrites. $C$, A cell with a fusiform soma and with multipolar $\pi$-shaped dendrites. Scale bar, $100 \mu \mathrm{m}$.

less, small groups of pyramidal and multipolar cells occurred in the cervical and lumbosacral segments, and groups of fusiform cells were common in the thoracic segments.

The longitudinal (segmental) distribution of lamina I STT cells was examined from the second cervical through the first coccygeal segments in all six cases. The pattern was similar in each case, with large concentrations of labeled cells in $\mathrm{C} 2$ and in the cervical (C5-8) and lumbar (L5-7) enlargements. The single owl monkey case (STM46), which had a small injection and a short survival time, differed in that there was a lower number of cells in $\mathrm{C} 2$ (Table 1) and no increase in the lumbosacral cord (Fig. 7A); these data were not included in the succeeding analyses. The average longitudinal distribution in the five cynomolgus monkeys is shown in Table 3. On average, 3630 lamina I STT cells were observed in the contralateral cord. The peak concentrations of labeled lamina I STT cells in the C2, C5-8, and L5-7 segments on average contained $7 \%, 31 \%$, and $13 \%$ of the entire population, respectively.

The longitudinal distribution of each of the three basic types of lamina I STT cells is shown in Figure $7 B$. These show similar overall patterns, with peak concentrations in the enlargements. However, the relative proportional distributions of the three cell

\begin{tabular}{|c|c|c|c|c|c|}
\hline Segment & $\begin{array}{l}\mathrm{F} \\
(\%)\end{array}$ & $\begin{array}{l}\mathrm{P} \\
(\%)\end{array}$ & $\begin{array}{l}\mathrm{M} \\
(\%)\end{array}$ & $\begin{array}{l}\mathrm{U} \\
(\%)\end{array}$ & $\begin{array}{l}\text { Mean } \\
\text { number }\end{array}$ \\
\hline $\mathrm{C} 2$ & 51 & 25 & 18 & 5 & 264 \\
\hline $\mathrm{C} 3$ & 51 & 25 & 16 & 8 & 214 \\
\hline $\mathrm{C} 4$ & 50 & 27 & 17 & 6 & 218 \\
\hline $\mathrm{C} 5$ & 44 & 32 & 19 & 5 & 255 \\
\hline C6 & 39 & 33 & 24 & 4 & 285 \\
\hline $\mathrm{C} 7$ & 38 & 32 & 25 & 5 & 306 \\
\hline $\mathrm{C} 8$ & 42 & 31 & 24 & 4 & 294 \\
\hline $\mathrm{T} 1$ & 57 & 23 & 15 & 5 & 149 \\
\hline $\mathrm{T} 2$ & 61 & 20 & 13 & 5 & 97 \\
\hline $\mathrm{T} 3$ & 63 & 21 & 12 & 4 & 75 \\
\hline $\mathrm{T} 4$ & 70 & 17 & 10 & 3 & 63 \\
\hline T5 & 69 & 18 & 8 & 4 & 47 \\
\hline T6 & 6 & 18 & 14 & 4 & 49 \\
\hline $\mathrm{T} 7$ & 65 & 21 & 10 & 3 & 40 \\
\hline $\mathrm{T} 8$ & 69 & 17 & 14 & 1 & 38 \\
\hline T9 & 71 & 18 & 9 & 3 & 48 \\
\hline $\mathrm{T} 10$ & 75 & 13 & 11 & 2 & 43 \\
\hline $\mathrm{T} 11$ & 70 & 15 & 12 & 3 & 48 \\
\hline $\mathrm{T} 12$ & 67 & 15 & 12 & 6 & 56 \\
\hline L1 & 58 & 20 & 16 & 6 & 65 \\
\hline L2 & 54 & 22 & 20 & 4 & 67 \\
\hline L3 & 44 & 26 & 22 & 7 & 92 \\
\hline L4 & 38 & 30 & 28 & 3 & 98 \\
\hline L5 & 32 & 32 & 32 & 4 & 135 \\
\hline L6 & 31 & 29 & 35 & 4 & 166 \\
\hline L7 & 29 & 33 & 32 & 5 & 158 \\
\hline S1 & 28 & 34 & 32 & 5 & 92 \\
\hline S2 & 34 & 23 & 37 & 6 & 64 \\
\hline S3 & 32 & 26 & 37 & 4 & 68 \\
\hline Co1 & 28 & 28 & 39 & 5 & 60 \\
\hline $\begin{array}{l}\text { Average } \\
\text { percentage }\end{array}$ & 46.6 & 26.4 & 22.1 & 4.9 & \\
\hline Average total & 1690 & 958 & 804 & 178 & 3630 \\
\hline
\end{tabular}

types differed over the length of the spinal cord. As shown in Figure $7 C$, the pyramidal and multipolar cells differed from the fusiform cells in their increased representations in the enlargements. In contrast, the fusiform cells had a proportionally lower representation at the enlargements and a greater representation in the rest of the cord. Thus, the three types of cells each formed about one-third of the labeled lamina I STT population in the enlargements (fusiform, 30-40\%; pyramidal, 30-35\%; and multipolar, 20-35\%), but in the thoracic cord the fusiform cells formed about two-thirds or more $(60-75 \%)$ of the population, with fewer pyramidal (15-25\%) and multipolar (10-15\%) cells. In addition, whereas the proportion of pyramidal cells was similar in the cervical and lumbar enlargements, there was a higher percentage of multipolar cells in the lumbosacral enlargement than in the cervical enlargement ( $35 \%$ vs $25 \%$ ), with the proportion of fusiform cells showing the opposite pattern (30\% vs 40\%). Although some variability was observed across animals, this was unrelated 

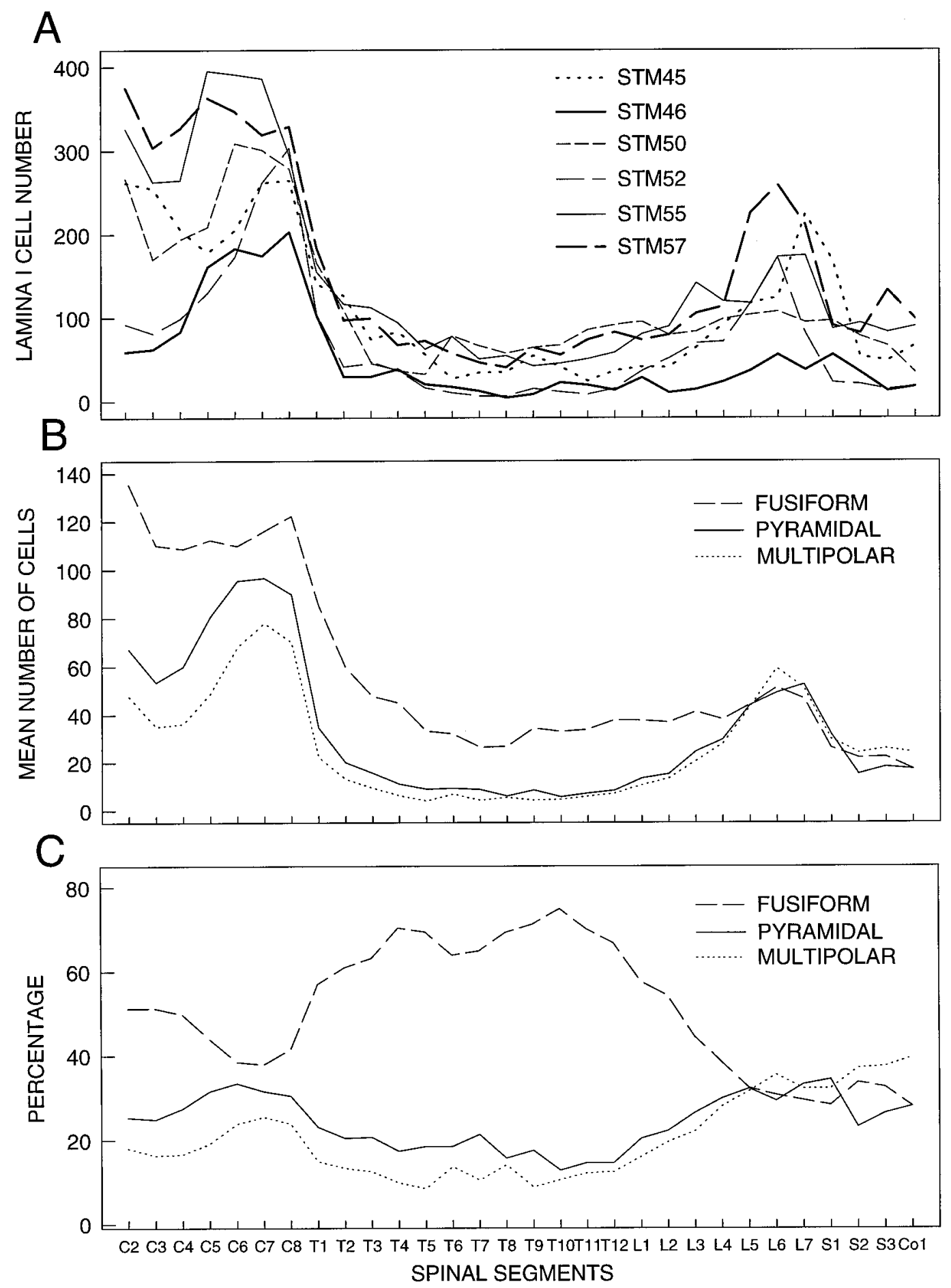

Figure 7. A graphic display showing the longitudinal (segmental) distribution of labeled lamina I STT cells over the length of the spinal cord (second cervical through first coccygeal segments). $A$, The distribution of the raw number of labeled lamina I STT cells in each of the six cases. Peak concentrations occurred at C2 and in the cervical and lumbosacral enlargements. Case STM46 (owl monkey, small injection, and short survival time) had a low number of cells and did not show peaks at $\mathrm{C} 2$ and the lumbar enlargement. $B$, The distribution of the mean number of each of the three types of lamina I STT cells in five cynomolgus monkeys (see Table 3). The number of fusiform cells was higher overall, but in the lumbosacral enlargement the three type of cells were almost equal in number. $C$, The distribution of the relative proportions of each of the three types of lamina I STT cells (see Table 3). The proportions of $\mathrm{P}$ and $\mathrm{M}$ cells increased in the enlargements relative to the proportion of fusiform cells.

to the absolute number of cells labeled in each case; the overall patterns were consistent across cases. The unclassified cells were of small number (1-8\%) throughout the spinal cord, and no obvious differences were observed in their distribution.

\section{DISCUSSION}

The present observations indicate that lamina I STT cells in the monkey, as in the cat, can be categorized comprehensively into 
three basic morphological types, fusiform, pyramidal, and multipolar, based on the criteria of somatal shape and primary dendritic orientation in the horizontal plane. These are the same basic morphological types of lamina I cells discriminated in Golgi studies in the cat by Gobel (1978) and in the rat by Lima and Coimbra (1986). The same types are also visible in the drawings of lamina I cells in the monkey made in the Golgi study of Beal et al. (1981), although a different categorization scheme based on dendritic microanatomy was used. The presence of these three basic cell types in lamina I thus seems to be a general mammalian feature.

The present observations are directly comparable to our previous findings on retrogradely CTb-labeled lamina I STT cells in the cat (Zhang et al., 1996). Fusiform, pyramidal, and multipolar cells were found in cat and in New World as well as Old World monkey. In both cat and monkey, these cell types have significantly different somatal sizes and numbers of dendrites. The sizes of each cell type and the overall morphology of the lamina I STT cells are remarkably similar between cat and monkey. In both, these cell types are differentially distributed longitudinally, consistent with the possibility of different functional roles (see below). Nonetheless, there are differences. There is a higher proportion of fusiform cells in the monkey; on average, we found $47 \%$ fusiform, $26 \%$ pyramidal, and $22 \%$ multipolar cells in the monkey, in contrast to $34 \%$ fusiform, $36 \%$ pyramidal, and $25 \%$ multipolar in the cat. The average raw number of labeled contralateral lamina I STT cells in the monkey is also considerably larger (3630) than in the cat (1360). Lamina I STT cells have a more angular and variegated appearance in the monkey than in the cat, and there is a greater diversity in shape within each basic cell type. We were able to recognize subtypes of each basic morphological shape in the monkey. Whereas examples of alternate shapes of fusiform and pyramidal cells were more infrequent in the cat, subtypes of multipolar cells were observed in both species. Yet, the relative frequency of occurrence differed. Quadrilateral and radiating multipolar cells were most common in both species, but the T-shaped multipolar cells that were occassionally seen in the cat were rare in the monkey, and the $\pi$-shaped lamina I STT cells often found in the monkey were almost never seen in the cat. Similarly, irregular fusiform cells, e.g., bipolar cells with a recurrent dendrite, that were seen in the monkey were almost never observed in the cat.

The present observations are consistent with the report by Willis et al. (1979) that projecting lamina I STT cells labeled retrogradely with HRP or with WGA*HRP in the monkey were "fusiform, pyriform, or triangular" based on observations in transverse and sagittal sections. Our present observations in the monkey and our prior observations in the cat, however, are not consistent with the report in the rat by Lima and Coimbra (1988) that most retrogradely HRP- or CTb-labeled lamina I STT cells were pyramidal in shape, with others belonging to their flattened (or multipolar) type. This could suggest a species difference. However, their report contained illustrations of labeled STT cells that could be regarded as fusiform, as noted previously (Zhang et al., 1996). In their retrograde study, they relied heavily on sagittal sections. In contrast, they made extensive use of horizontals in their preceding Golgi study, as did Gobel (1978) in his Golgi study in the cat. As discussed earlier (Zhang et al., 1996), lamina I cell shapes are consistently most distinguishable in the horizontal plane in which they arborize.

There is considerable evidence suggesting that the three basic morphological cell types in the cat may correspond to the three major physiological classes of lamina I STT cells. The NS, COLD, and HPC cells have significantly different ascending conduction velocities (Craig and Kniffki, 1985; Craig and Serrano, 1994), and they have different patterns of axonal projections within the thalamus (Craig and Dostrovsky, 1991; Dostrovsky and Craig, 1993), in addition to their different stimulus-response properties (Craig and Kniffki, 1985; Craig, 1996) and different responses to systemic opiates and to descending inhibition (Dawson et al., 1981; Dostrovsky et al., 1983; Mokha et al., 1987; Craig and Serrano, 1994; Craig, 1996). These characteristics indicate that the projecting axons of these robust physiological classes differ anatomically, and this implies the possibility that their somata may also be morphologically distinguishable, as in other systems (for example, see Tamamaki et al., 1995). This possibility has received direct support from recent preliminary findings based on intracellular biotin labeling of single identified lamina I cells in the cat. These data indicate that fusiform cells are NS, pyramidal cells are COLD, and multipolar cells are generally HPC (Han and Craig, 1994; Han, Zhang, and Craig, manuscript in preparation).

Thus, the identification of distinct morphological types of lamina I STT cells in the monkey may have direct relevance to the physiological characterization of this pathway. In contrast to the cat, most prior physiological studies of STT cells in the monkey described only NS and WDR cells in lamina I and few or no thermoreceptive neurons (Willis et al., 1974; Burton, 1975; Kumazawa et al., 1975; Kumazawa and Perl, 1978; Iggo and Ramsay, 1976; Price et al., 1978; Ferrington et al., 1987). Nonetheless, in a recent study NS, COLD, and HPC lamina I STT cells having the same characteristics as those in the cat were identified in the L7 segment of the monkey (Dostrovsky and Craig, 1996). These cells were antidromically activated from the dedicated lamina I STT relay nuceus in posterolateral thalamus of the monkey, the posterior ventral medial nucleus (VMpo; Craig et al., 1994; Craig, 1996), and thus, were probably not observed in prior studies in which antidromic electrodes had been placed in the ventral posterior lateral (VPL) nucleus. The identification of the same physiological classes of lamina I STT neurons in the monkey and the cat is consistent with the presence of the same basic morphological cell types. Thus, it seems reasonable to consider that a morphological/physiological correspondence may exist in both species.

Additional evidence in support of this possibility is provided by the recent observation of a discrete zone of COLD cells in the interstitial portion of lamina I in the trigeminal dorsal horn of the owl monkey (Blomqvist et al., 1995). In this cytoarchitectonically distinct region, virtually all lamina I trigeminothalamic cells are pyramidal cells, whereas the adjacent parts of lamina I contain fusiform and multipolar neurons. Further, this zone contrasts with the adjacent portions of lamina I immunohistochemically in that it contains few fibers immunoreactive for substance P, enkephalin, or serotonin, which is consistent with the differential effects that both opiates and descending influences have on COLD versus NS or HPC lamina I cells (Dawson et al., 1981; Dostrovsky et al., 1983; Mokha et al., 1987; Craig and Serrano, 1994; Craig, 1996).

We conclude that three basic morphological types of lamina I STT neurons with differential longitudinal distributions are present in the monkey that compare favorably with the types previously identified in Golgi material and in comparable experiments in the cat. These morphological cell types may correspond to different functional classes of nociceptive and thermoreceptive lamina I STT neurons in both the monkey and the cat. Based on anterograde PHA-L findings of lamina I projections to the spinal 
sympathetic nuclei, to the preautonomic and homeostatic regions of the brainstem, and to specific regions of the thalamus associated with pain and temperature sensibility (Craig, 1993, 1995; Craig et al., 1994; Craig, 1996), it has been proposed that the lamina I projection system distributes modality-selective afferent sensory information relevant to the physiological status and maintenance of the tissues and organs of the entire mammalian organism. In particular, the lamina I spino-thalamo-cortical projection to the insula via VMpo has been suggested to provide the basis for an enteroceptive sense of the physiological condition of the body itself (Craig, 1996). Thus, the identification of anatomical and functional subtypes of lamina I projection neurons enables further analysis of the roles of this system in homeostasis, in pain and temperature sensation, and in the cortical representation of the status of all tissues of the body.

\section{REFERENCES}

Apkarian AV, Hodge CJ (1989) Primate spinothalamic pathways. I. A quantitative study of the cells of origin of the spinothalamic pathway. J Comp Neurol 288:447-473.

Beal JA, Penny JE, Bicknell HR (1981) Structural diversity of marginal (lamina I) neurons in the adult monkey (Macacca mulatta) lumbosacral spinal cord: a golgi study. J Comp Neurol 202:237-254.

Blomqvist A, Zhang ET, Craig AD (1995) A thermoreceptive subregion of lamina I in N. caudalis of the owl monkey. Soc Neurosci Abstr 21:108.

Bowsher D, Abdel-Maguid TE (1984) Superficial dorsal horn of the adult human spinal cord. Neurosurgery 15:893-899.

Burton H (1975) Responses of spinal cord neurons to systematic changes in hindlimb skin temperatures in cats and primates. J Neurophysiol 38:1060-1079.

Bushnell MC, Craig AD, Reiman EM, Yun LS, Evans A (1995) Cerebral activation in the human brain by pain, temperature and an illusion of pain. Soc Neurosci Abstr 21:1637.

Carstens E, Trevino DL (1978) Laminar origins of spinothalamic projections in the cat as determined by the retrograde transport of horseradish peroxidase. J Comp Neurol 182:151-166.

Casey KL, Minoshima S, Morrow TJ, Koeppe RA (1996) Comparison of human cerebral activation patterns during cutaneous warmth, heat pain, and deep cold pain. J Neurophysiol 76:571-581.

Christensen BN, Perl ER (1970) Spinal neurons specifically excited by noxious or thermal stimuli: marginal zone of the dorsal horn. J Neurophysiol 33:293-307.

Craig AD (1991) Spinal distribution of ascending lamina I axons anterogradely labeled with Phaseolus vulgaris leucoagglutinin (PHA-L) in the cat. J Comp Neurol 313:377-393.

Craig AD (1993) Propriospinal input to thoracolumbar sympathetic nuclei from cervical and lumbar lamina I neurons in the cat and the monkey. J Comp Neurol 331:517-530.

Craig AD (1995) Distribution of brainstem projections from sipnal lamina I neurons in the cat and the monkey. J Comp Neurol 361:225-248.

Craig AD (1996) Pain, temperature, and the sense of the body. In: Somesthesis and the neurobiology of the somatosensory cortex (Franzen O, Johannson R, Terenius L, eds), pp 27-39. Basel: Birkhäuser.

Craig AD, Dostrovsky JO (1991) Thermoreceptive lamina I trigeminothalamic neurons project to the nucleus submedius in the cat. Exp Brain Res 85:470-474.

Craig AD, Kniffki KD (1985) Spinothalamic lumbosacral lamina I cells responsive to skin and muscle stimulation in the cat. J Physiol (Lond) 365:197-221.

Craig AD, Serrano LP (1994) Effects of systemic morphine on lamina I spinothalamic tract neurons in the cat. Brain Res 636:233-244.

Craig AD, Zhang ET (1996) Anterior cingulate projection from MDvc (a lamina I spinothalamic target in the medial thalamus of the monkey). Soc Neurosci Abstr 22:111.

Craig AD, Linington AJ, Kniffki KD (1989) Cells of origin of spinothalamic tract projections to the medial and lateral thalamus in the cat. J Comp Neurol 289:568-585.

Craig AD, Bushnell MC, Zhang ET, Blomqvist A (1994) A thalamic nucleus specific for pain and temperature sensation. Nature 372:770-773.

Craig AD, Krout K, Zhang ET (1995) Cortical projections of VMpo, a specific pain and temperature relay in primate thalamus. Soc Neurosci Abstr 21:1165.

Dawson NJ, Dickenson AH, Hellon RF, Woolf CJ (1981) Inhibitory controls on thermal neurones in the spinal trigeminal nucleus of cats and rats. Brain Res 209:440-445.

Dostrovsky JO, Craig AD (1993) Antidromic identification of nociceptive lamina I cell terminations in the cat thalamus. Soc Neurosci Abstr 19:1572.

Dostrovsky JO, Craig AD (1997) Cooling-specific spinothalamic neurons in the monkey. J Neurophysiol, in press.

Dostrovsky JO, Shah Y, Gray BG (1983) Descending inhibitory influences from periaqueductal gray, nucleus raphe magnus, and adjacent reticular formation: II. Effects on medullary dorsal horn nociceptive and nonnociceptive neurons. J Neurophysiol 49:948-960.

Ericson H, Blomqvist A (1988) Tracing of neuronal connections with cholera toxin subunit B: light and electron microscopic immunohistochemistry using monoclonal antibodies. J Neurosci Methods 24:225-235.

Ferrington DG, Sorkin LS, Willis WD (1987) Responses of spinothalamic tract cells in the superficial dorsal horn of the primate lumbar spinal cord. J Physiol (Lond) 388:681-703.

Ganchrow D (1978) Intratrigeminal and thalamic projections of nucleus caudalis in the squirrel monkey (Saimiri sciureus): a degeneration and autoradiographic study. J Comp Neurol 178:281-312.

Gobel S (1978) Golgi studies of the neurons in layer I of the dorsal horn of the medulla (trigeminal nucleus caudalis). J Comp Neurol 180:375-394.

Han ZS, Craig AD (1994) Morphological characteristics of physiologically identified lamina I cells in cats. Soc Neurosci Abstr 20:547.

Hylden JLK, Hayashi H, Dubner R, Bennett GJ (1986) Physiology and morphology of the lamina I spinomesencephalic projection. J Comp Neurol 247:505-515.

Iggo A, Ramsey RL (1976) Thermosensory mechanisms in the spinal cord of monkeys. In: Sensory functions of the skin in primates (Zotterman Y, ed), pp 285-304. Oxford: Pergamon.

Jones AKP, Brown WD, Friston KJ, Qi LI, Frackowiak RSJ (1991) Cortical and subcortical localization of response to pain in man using positron emission tomography. Proc R Soc Lond [Biol] 244:39-44.

Kumazawa T, Perl ER (1978) Excitation of marginal and substantia gelatinosa neurons in the primate spinal cord: indications of their place in dorsal horn functional organization. J Comp Neurol 177:417-434.

Kumazawa T, Perl ER, Burgess PR, Whitehorn D (1975) Ascending projections from marginal zone (lamina I) neurons of the spinal dorsal horn. J Comp Neurol 162:1-12.

Light AR, Trevino DL, Perl ER (1979) Morphological features of functionally defined neurons in the marginal zone and substantia gelatinosa of the spinal dorsal horn. J Comp Neurol 186:151-172.

Light AR, Sedivec MJ, Casale EJ, Jones SL (1993) Physiological and morphological characteristics of spinal neurons projecting to the parabrachial region of the cat. Somatosens Mot Res 10:309-325.

Lima D, Coimbra A (1986) A Golgi study of the neuronal population of the marginal zone (lamina I) of the rat spinal cord. J Comp Neurol 244:53-71.

Lima D, Coimbra A (1988) The spinothalamic system of the rat: structural types of retrogradely labelled neurons in the marginal zone (lamina I). Neuroscience 27:215-230.

Mokha SS, Goldsmith GE, Hellon RF, Puri R (1987) Hypothalamic control of nocireceptive and other neurones in the marginal layer of the dorsal horn of the medulla (trigeminal nucleus caudalis) in the rat. Exp Brain Res 65:427-436.

Nathan PW, Smith MC (1979) Clinico-anatomical correlation in anterolateral cordotomy. In: Advances in pain research and therapy (Bonica JJ, ed), Vol 3, pp 921-926, New York: Raven.

Norrsell U (1979) Thermosensory defects after cervical spinal cord lesions in the cat. Exp Brain Res 35:479-494.

Perl ER (1984) Pain and nociception. In: Handbook of physiology, Vol III, Sensory processes, Sec 1, The nervous system (Darian-Smith I, ed), pp 915-975, Bethesda: American Physiological Society.

Price DD, Hayes RL, Ruda M, Dubner R (1978) Spatial and temporal transformations of input to spinothalamic tract neurons and their relation to somatic sensations. J Neurophysiol 41:933-947.

Ralston HJ, Ralston DD (1992) The primate dorsal spinothalamic tract: Evidence for a specific termination in the posterior nuclei $(\mathrm{Po} / \mathrm{SG})$ of the thalamus. Pain 48:107-118. 
Rexed B (1952) The cytoarchitectonic organization of the spinal cord in the cat. J Comp Neurol 96:415-495.

Schoenen J (1982) The dendritic organization of the human spinal cord: the dorsal horn. Neuroscience 7:2057-2087.

Snyder RL (1982) Light and electron microscopic autoradiographic study of the dorsal root projections to the cat dorsal horn. Neuroscience 7:1417-1438.

Steedman WM, Molony V, Iggo A (1985) Nociceptive neurones in the superficial dorsal horn of cat lumbar spinal cord and their primary afferent inputs. Exp Brain Res 58:171-182.

Talbot JD, Marrett S, Evans AC, Meyer E, Bushnell MC, Duncan GH (1991) Multiple representations of pain in human cerebral cortex. Science 251:1355-1358.

Tamamaki N, Uhlrich DJ, Sherman SM (1995) Morphology of physiologically identified retinal $\mathrm{X}$ and $\mathrm{Y}$ axons in the cat's thalamus and midbrain as revealed by intraaxonal injection of biocytin. J Comp Neurol 354:583-607.
Willis WD, Trevino DL, Coulter JD, Maunz RA (1974) Responses of primate spinothalamic tract neurons to natural stimulation of hindlimb. J Neurophysiol 37:358-372.

Willis WD, Kenshalo DR, Leonard RB (1979) The cells of origin of the primate spinothalamic tract. J Comp Neurol 188:543-574.

Willis WD (1985) The pain system. Basel: Karger.

Woolf CJ, Fitzgerald M (1983) The properties of neurones recorded in the superficial dorsal horn of the rat spinal cord. J Comp Neurol 221:313-328.

Zhang ET, Craig AD (1995) Morphological classes of retrogradely labeled lamina I spinothalamic neurons in the monkey. Soc Neurosci Abstr 21:645.

Zhang ET, Craig AD (1996) Origin of spinothalamic input to VMpo in the monkey. Soc Neurosci Abstr 22:109.

Zhang ET, Han ZS, Craig AD (1996) Morphological classes of spinothalamic lamina I neurons in the cat. J Comp Neurol 367:537-549. 